\title{
African fire histories and fire ecologies
}

Colin J. Courtney-Mustaphi',2,3, D. Colombaroli, ${ }^{4,5}$, B. Vannière ${ }^{6}$, C. Adolf7, L. Bremond ${ }^{8,9}$, J. Aleman $^{10}$ and the Global Paleofire Working Group (GPWG2)

Nairobi, Kenya, 19-22 July 2018

Patterns of fire are changing across African savannahs, rainforests, fynbos, woodlands, and Afroalpine and montane forests, with direct environmental and socio-ecological consequences. Fire variability has implications for biodiversity (Beale et al. 2018), vegetation patterns, grazing quality, carbon emissions, protected area management, and landscape heterogeneity.

Fire is a crucial component of savannah functioning and structure and is essential for maintaining its biodiversity. Long-term records are key to understanding drivers of fire variability and contextualize recent and ongoing land-use changes that altered fire responses to climate and vegetation changes (e.g. Ekblom and Gillson 2010, Colombaroli et al. 2014). As indigenous forest loss continues and modification through selective harvesting and land-use encroachment accelerate forest changes, the importance of historical disturbance regimes is increasingly relevant for assessing past ranges of variability and to define management targets that support more resilient socioecological systems (Whitlock et al. 2018). But how can the research community engage and integrate with land-management practitioners and policy developers? And how can we promote knowledge transfer and collaborative capacity between the international community and the next generation of African scientists?

Such themes were explored and discussed during a GPWG2 workshop following the African Quaternary Association (AFQUA) conference. The workshop gathered 18 participants from 12 countries, including 10 researchers from Africa-based institutions. It opened with introductory lectures and laboratory practical courses on study-site selection, sampling techniques, laboratory preparation and charcoal morphology analyses, and a discussion on charcoal calibration approaches for African sites (Ekblom and Gillson 2010; Adolf et al. 2018; Hawthorne et al. 2018; Fig. 1). Participants were introduced to quantitative paleoenvironmental data analysis techniques using $R$; those included reconstructing savannah fire responses to precipitation and biomass using Generalized Additive Models (GAMs) with data from Lake Naivasha, Kenya (Colombaroli et al. 2014). Dedicated breakout sessions involved data mining using the Global Charcoal Database (GCD) and examinations of spatiotemporal knowledge gaps, notably for western and central Africa, where spatial coverage is scant and several published records need to be imported in the GCD (Fig. 1e). The data gaps are also apparent from the driest and wettest ends of the precipitation gradient, and mostly lacking from mangrove, Afroalpine, and dry woodland study sites. Furthermore, only a limited number of study sites are located near archaeological sites, limiting analyses on human-environment interactions (Marchant et al. 2018). The discussion highlighted the need to develop high-quality charcoal series that account for potential biases in sediment accumulation and related chronological uncertainties (Colombaroli et al. 2014).
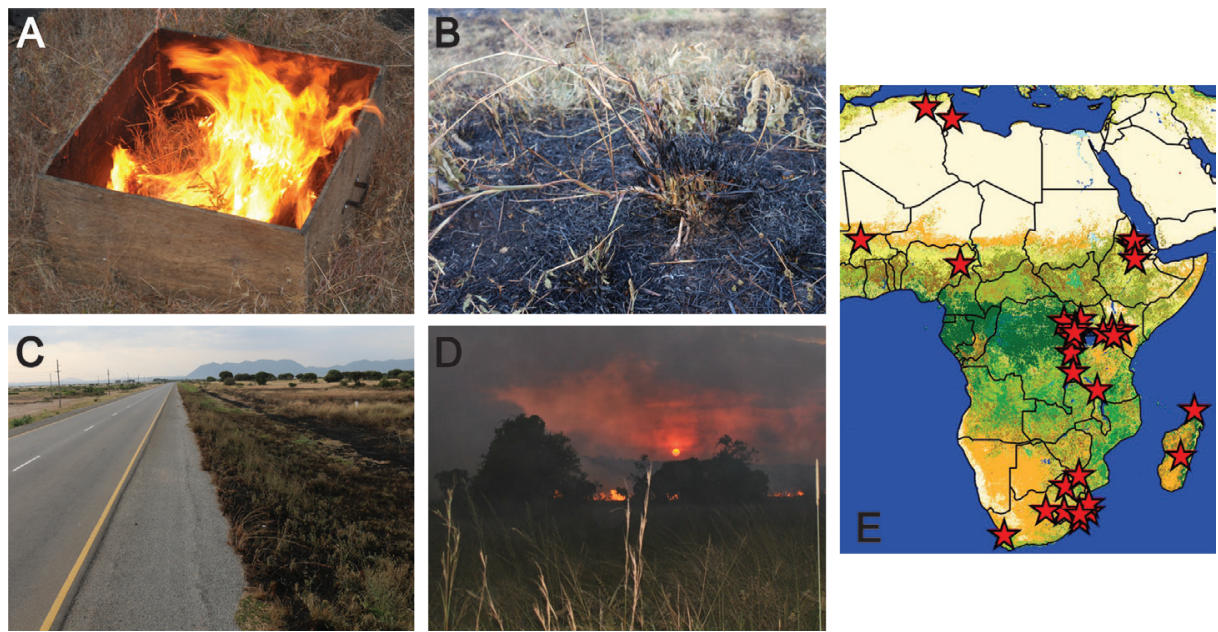

Figure 1: (A) Experiments, like this 1x1 m controlled grass burning, help relate vegetation-fire-charcoal proxy measurements to paleoecological charcoal records. (B) Residual culms and mainstems from grazing and burning that will regrow leaves and inflorescence. (C) Roads and linear infrastructure increase fragmentation altering spatial complexity for fires. (D) Grass and woody fuels burning near Klein's Camp, Serengeti National Park, Tanzania, 16 July 2016. (E) Published charcoal records that participants identified during a literature review, including records absent from the Global Charcoal Database (Map source: due.esrin.esa.int/page_globcover.php). Photographs: Colin Courtney-Mustaphi.
Finally, participants discussed the contribution of paleofire data to land-management applications (Fig. 1), including conservation and fire policy; a theme specifically addressed by the GPWG DiverseK frameworkworkshop (see Colombaroli et al., this issue). Participants were assigned sub-regions and discussed challenges and alternatives for managing fire as a component in socioecological systems (Whitlock et al. 2018). The discussion highlighted how resource management in the Menengai Forest, Kenya, and areas of southwest Madagascar are impacted by logging, unauthorized burning, resource extraction, and invasive species; while in the Bale Mountain National Park, Ethiopia, the existing contestation between pastoralists and conservation requirements necessitates new approaches to maintain ecosystem services and promote co-benefits. Approaches combining paleoecology and qualitative, local content optimize bidirectional knowledge transfers and encourage long-term engagement between the GPWG2 and new active members of the research community.

\section{AFFILIATIONS}

'Department of Environmental Sciences, University of Basel, Switzerland

2Department of Archaeology and Ancient History, Uppsala University, Sweden

${ }^{3}$ Environment Department, University of York, UK ${ }^{4}$ Department of Geography, Royal Holloway University of London, UK

Institute of Plant Sciences, University of Bern, Switzerland ${ }^{6}$ CNRS-UMR Chrono-environnement, Université Bourgogne Franche-Comté, Besançon, France 'Department of Zoology, University of Oxford, UK Institut des Sciences de l'Evolution de Montpellier (CNRS, IRD, EPHE), Université de Montpellier, France 'École Pratique des Hautes Études, PSL Research University, Paris, France

${ }^{10}$ Département de Géographie, Université de Montréal, Canada

\section{CONTACT}

Colin J. Courtney-Mustaphi: colin.courtney-mustaphi@ unibas.ch

\section{REFERENCES}

Adolf C et al. (2018) Glob Ecol Biogeog 27: 199-212

Beale C et al. (2018) Ecol Lett 21: 557-567

Colombaroli D et al. (2014) Glob Change Bio 20:

$$
\text { 2903-2914 }
$$

Ekblom A, Gillson L (2010) Holocene 20: 1063-1077

Hawthorne D et al. (2018) Quat Int 488: 3-17

Marchant R et al. (2018) Earth-Sci Rev 178: 322-378

Whitlock C et al. (2018) Biol Conserv 32: 84-97 